NBSIR 74-459(R)

\title{
Projects and Publications of the Applied Mathematics Division
}

Applied Mathematics Division Institute for Basic Standards

National Bureau of Standards

Washington, D. C. 20234

\section{A Semi-Annual Period}

January-June 1973

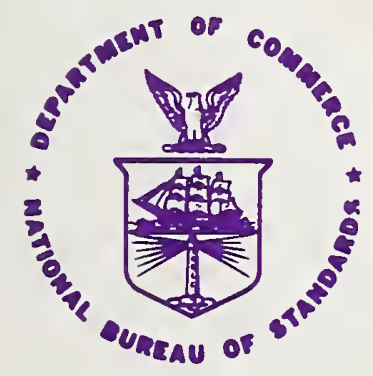

\section{U. S. DEPARTMENT OF COMMERCE}

NATIONAL BUREAU OF STANDARDS

\section{0}

.056

非4-459

(R) 

NBSIR 74-459(R)

\section{PROJECTS AND PUBLICATIONS OF THE APPLIED MATHEMATICS DIVISION}

Applied Mathematics Division Institute for Basic Standards National Bureau of Standards

Washington, D. C. 20234

A Semi-Annual Period

January-June 1973

U. S. DEPARTMENT OF COMMERCE, Frederick B. Dent, Secretary NATIONAL BUREAU OF STANDARDS, Richard W. Roberts. Director 
APPLIED MATHEMATICS DIVISION (205.00): Conducts research and provides consulting services to the Bureau and other Federal agencles in various fields of mathematics important in sclence and englneering, including automatic data processing and operations research, with emphasis on statistical, numerical and combinatorial analysis, and on mathematical physics. Develops tools for mathomatical work such as mathematical tables, handbooks, manuals, mathematical models and computational methods, and advises on their use. Provides training in disciplines related to these functions.

MATHEMATICAL ANALYSIS SECTION (205.01): Conducts research and provides consulting services in core and applied mathematics as they impact. on science and engineering, involving research supporting the advancement of computation, particularly in the development of computing algorithms and criteria for their evaluation. Performs mathematical analyais of complex physical systems for the purpose of developing rigorous analytic procedures. Simulates the behavior of physical systems by means of electronic computers, using approximation techniques and semi-analytic methods. Studies the properties and repregentations of special functions encountered in research and consultation. Develops methods for computing these special functions, and critically evaluates methods comronly used. Collaborates with representatives of government agencies, industry, and universitieg in an effort of extensive testing, evaluation and documentation of algorithms and computer programs for scientific calculation.

OPERATIONS RESEARCH SECTION (205.02): Develops and applies mathematical-computational techniques for and provides consulting services in the analysis, improvement or optimization of complex systems or activity patterns. Conducts investigations in the art of constructing useful mathematical models of complex systems. Studieg such systems by applying analytic or simulation methods. Applies these techniques to problems arising in the work of the Bureau or of other Government agencies lacking speciallzed pergonnel in this field. Performs research in underlying areas of mathematics, such as linear programing, the theory of linear graphs, and the theory of strategic contests.

STATISTICAL ENGINEERING SECTION (205.03): Provides consulting services in the application of mathematical statistics to physical science experiments and engineering tests, particularly in the design of experiments and in the analysis and interpretation of data. Contributes to the development of appropriate tatistical techniques on a foundation of research on pertinent topics in probability and mathematical statistics. Conducts studies of computational methods, and prepares reports, manuals, tables, and handbooks to facilitate the application of modern statistical methods. 


\section{Contents}

Status of Projects as of June 30,1973............... 1

1. Mathematical analysis. .............. 1

2. Operations research.............. 6

3. Probability and mathematical statistics. . . . . . . . 9

4. Statistical engineering services. . . . . . . . . . 11

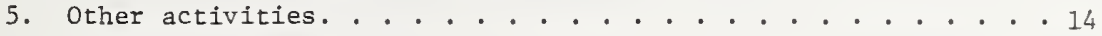

Lectures and technical meetings. . . . . . . . . . . 19

Publication activities. . . . . . . . . . . . . 22

- Only unclassified material is included in this report. 


\title{
APPLIED MATHEMATICS DIVISION
}

\author{
January 1, 1973 through June 30, 1973
}

TECHNICAL ADVISORY PANEL

Murray S. Klamkin, Ford Scientific Laboratory, Chairman

Car1 A. Bennett, Battelle-Nor thwest

Richard W. Haming, Bell Telephone Laboratories

H. 0. Hartley, Texas A.\& M. University
M. H. Martin, University of Maryland

Alan J. Perlis, Yale Univeraity

John Todd, California Institute of Technology

\section{DIVISION OFFICE}

Burton H. Colvin, Ph. D., Chief

Susanne M. Nee, Secretary

\author{
Russe11 A. Kirsch, M. S. \\ Irene A. Stegun, M. A. \\ Anne $\mathrm{H}$. Meininger, B. A. \\ Ruth Zucker, B. A. \\ Donald J. Orser, B. S. \\ Morris Newman, Ph. D., Senior Research Mathematician \\ Doris M. Burre11, Secretary \\ Charles R. Johnson, Ph. D.** \\ Justin C. Schaffert* \\ Susan E. Landau***
}

MATHEMATICAL ANALYSIS SECTION, Hans J. Oser, Ph. D., Chief

Jeffrey T. Fong, Ph. D.

Seymour Haber, Ph. D.

Frederick C. Johnson, Ph. D.

Regina Kopec, Secretary

OPERATIONS RESEARCH SEC
Tyrone B. Ayers, B. S. 1
Jack Edmonds, M. A.

Judith F. Gilsinn, M. S.
S. Richard Kraft, Ph. D. Joseph Lehner, $\mathrm{Ph}$. D.* Chising A. Liao, M. A. ${ }^{3}$ Daniel W. Lozier, M. A.
Frank W. J. Olver, D. Sc.* George Reitwiesner, M. S. 2 Walter L. Sadowski, Ph. D. David J. Sookne, M. A.

STATISTICAL ENGINEERING LABORATORY, Joan R. Rosenblatt, Ph. D., Chief Hsien H. Ku, Ph. D., Ass't Chief

Wesley L. Nicholson, Ph. D. IBS Visiting Scientist

Shirley G. Bremer, B. S.* Eleanor S. Brown* Beverly J. Clipper, Secretary Veronica Connor, Secretary Janet R. Donaldson
James J. Filliben, Ph. S. David Hogben, Ph. D. John F. LaBrecque, M. A. T. ${ }^{\circ}$ James A. Lechner, Ph. D. Delmas M. Maxwe11
Mary G. Natrella, B. A.* Sally T. Peavy, B. S.* Peter V. Tryon, Ph. D. ${ }^{\circ 0}$ Roy H. Wampler, M. A.

\footnotetext{
*Part-time

On Leave of Absence

**Postdoctoral Research Associate ${ }^{\circ}$ Located at NBS Boulder Labs. $* * *$ Guest Worker
}

$1_{\text {Detailed from NBS Personnel }}$ Division(Quality Staffing Program) ${ }^{2}$ Reemployed Annuitant

${ }^{3}$ Presidential Intern 


\section{MATHEMATICAL ANALYSIS}

RESEARCH IN MATHEMATICAL ANALYSIS

Task 20540-12-205141/55-57

$1550-11$

Origin: NBS

Manager: H.J. Oser

Authorized $9 / 1 / 54$

Ful1 task description: July - September 1954 issue, p. 27

Status: Continued

An extensive revision of a paper by Kraft entitled "An Existence Theorem for a Linear Transport Equation" was completed. This paper has been split into two papers. The first is entitled "A Rate of Convergence Inequality for Semidiscretizations of a Linear Transport Equation", the second paper carries the same title as the original. Both papers have been typed and minor corrections are belng made.

A paper by Kraft on fundamental solutions for systems of O.D.E.'s was completed. Minor corrections are being made before submitting the manuscript for publication.

A key step (computing "angle factors") in Kraft's program for numerical solution of the integral equation of interreflections was completed. He intends to compare his procedure(for computing "angle factors") with analytical bench marks and submit the results for publication.

In collaboration with the Electronic Technology Division, S.R. Kraft studied mathematical models of semiconductor doping. It is important in the manufacturing process of "chips" to control the density distribution of defects in the silicon lattice which are introduced through foreign atoms such as phosphorus and boron. The "doping" is affected through thermal oxidation and diffusion. The present formulation led mathematically to a system of Volterra Integral Equations. The numerical solution of these singular equations is in progress at this time.

Kraft has found a way to apply some results of his on "Riemann functions" to obtain generalizations of Gronwall's inequality. These results have applications to uniqueness and stability of certain types of partial differential equations. These ideas are being prepared for publication.

Seymour Haber devised a method for numerical evaluation of certain 5-fold integrals arising in the study of the response of tall buildings to turbulent winds. The work was done in consultation with Dr. E. Simlu of the Center for Building Technology; programs for evaluating the integrals and related parameters describing properties of bulldings were written by D. Sookne and D. Lozier. It is hoped that in the future these programs may be put into a form which will make them widely available to engineers and architects.

S. Haber and 0. Shisha of the Naval Research Laboratory continued their study of the representation of improper Riemann integrals as limits of Riemann sums, and of related questions about the numerical evaluation of such integrals. They completed a paper on this subject.

S. Haber calculated explicit error bounds for a simplified form of an extremely accurate quadrature formula due to Frank Stenger. 


\section{MATHEMATICAL ALGORITHMS}

Task 205-12-2050143

Origin: NBS (RTS)

Authorized 7/1/72

Manager: H.J. Oser

Status: Continued

Results of the testing of the UNIVAC FORTRAN Library of mathematical functions have been submitted to NBS Journal of Research, Section B. Lozier and Sadowski continued the development of the Bit Comparison Package to handle comparison between reference values and computer results to any number of bits. Thus the Bit Comparison Package can be used in testing minicomputer libraries.

Preliminary work on testing of the FORTRAN 1ibrary on the Interdata 70 computer was undertaken in support of the dimensional metrology program at IBS. This work will be continued. Albert Liao participated in several phases of this work.

David J. Sookne had four papers accepted by the NBS J. of Research,B. Two contain algorithms and FoRTRAN programs for Bessel functions $I_{n}(x)$ and $J_{n}(x)$ for real and complex arguments, the other two are devoted to the certification of these computer programs.

Frank W.J. Olver has constructed a complete set of algorithms for the computation of associated Legendre functionsfor arbitrary real values of the argument and degree and integer values of the order. The algorithms await testing before publication.

\section{Publications:}

(1) A Bit Comparison Program for Algorithm Testing. D.W. Lozier, L.C. Maximon and W.L. Sadowski. The Computer Journal, Vo1. 16, No. 2, 1973, pp. 111-117.

(2) Performance Testing of a FORTRAN Library of Mathematical Function Routines - A Case Study in the Application of Testing Techniques. D.W. Lozier, L.C. Maximon and W.L. Sadowski. Accepted for publication by NBS Journal of Research, Sec. B.

(3) Bessel Functions of Real Argument and Integer Order. D.J. Sookne. To appear in NBS Journal of Research, Sec. B.

(4) Certification of BESLRI. D.J. Sookne. To appear in NBS Journal of Research, Sec. B.

(5) Bessel Functions $I$ and $J$ of Complex Argument and Integer Order. D.J. Sookne. To appear in NBS Journal of Research, Sec. B.

(6) Certification of BESLCI. D.J. Sookne. To appear in NBS Journal of Research, Sec. B. 
Manager: Walter L. Sadowski

Objective: To test, document and validate a mathematical software system consisting of an arithmetic unit for extended precision calculations and a library of elementary functions. To develop, test and validate a preprocessor that will enable a computer user to declare certain variables in a FoRTRAN program to be extended precision and run the program in extended precision without further modifications.

Status: New

Daniel Lozier and Walter Sadowski began work to test and validate a Super Precision Package developed by William $\mathrm{T}$. Wyatt at the Harry Diamond Laboratories. In addition to the design of tests intended to validate the individual components of the package, heavy emphasis was placed on the documentation and verification of the mathematical algorithms used. Furthermore, uniform coding conventions were introduced and program flow simplified wherever it was felt that this would contribute to the understanding and ease of maintenance of the package. The result of this was the development of a "testable" version of the main arithmetic routines that w11 materially contribute to the information collected in the field tests.

Don Orser, in consultation with Lozier and Sadowski has written the first pass of the preprocessor. This part does the scanning and parsing of the FORTRAN text. The work on this project continues. 


\section{CONSULTATION IN MATHEMATICAL OPERATIONS RESEARCH}

Origin and Sponsor: NBS

Authorized $12 / 30 / 60$

Manager: A.J. Goldman

Full task description: October-December 1960 issue, p.3

\section{Status: CONTINUED}

(1) Section staff provided miscellaneous consulting and advisory services in 146 recorded instances, 83 involving assistance to NBS staff. These instances totalled to 735 man-hours. One new source was a number of inquiries stimulated by L.S. Joel's arranging a pair of lectures (and delivering one of them), on "cluster analysis" and related techniques, in the Division's Expository Seminar series. Other agencies assisted included DOC (BDC), OST, HEW, NSF, and various DOD units.

(2) A.J. Goldman continued service as representative of the 0perations Research Society of America (ORSA) to the Conference Board of the Mathematical Sciences (CBMS), beginning service on the Board's Nominations Committee and organizing/chairing a session on "Mathematical Modelling in the Decision Sciences" for the $1 / 73$ joint national mathematical-society meeting. He also continued as Associate Editor of ORSA's "Transportation Science" journal, and as NBS representative to the Mathematical Sciences Division of the National Research Council.

(3) Goldman continued service as a consultant to NBS' Experimental Technological Incentives Program (ETIP), in particular helping to monitor contracted studies on the roles of government procurement and of market aggregation as mechanisms to promote innovation. (Reported here for convenience; supported under Project 1150068.)

\section{Publications}

(1) A.J. Goldman. The adequacy of management science technology for non-military applications in the Federal government. To appear in Proc., Amer. Soc. Public Admin. Workshop on Management Science in the Federal Government $(11 / 69)$.

(2) A.J. Goldman. Product solutions and separation of variables. Journal of Research NBS, 76B (1972), 201-204.

COMBINATORIAL METHODS

Task 205-12-2050152

Origin and Sponsor: NBS

Authorized $12 / 30 / 60$

Manager: A.J. Goldman

Full task description: October-December 1964 issue, p.3; Apri1-June 1962, p.15

\section{Status: TERMINATED}

(1) Documentation of work by J. Gilsinn and C. Witzgall, on comparative evaluation of shortest-path algorithms, was published. The study showed that order-of-magnitude gains in efficiency of solution can be obtained by proper matching of calculation method with network characteristics. The latter include more than the mere numbers of nodes and links; the distinction between "long thin" and "squareish" configurations is also important, as is the variation in link-lengths. Algorithm performance can be extremely sensitive to what might be regarded as minor details of a method. The study identified 3 out of some 30 algorithms for recommendation, together with criteria for choosing among the 3 in particular cases. Its results should assist the over 300 million shortest-path calculations made annually, and have already permitted cutting an early estimate of computation effort by $2 / 3$ in an NBS project involving determination of 21 million shortest paths.

(2) L.S. Joel investigated some questions of convex-hull determination which arise in seeking to solve certain combinatorial optimization problems by means of linear programming. In particular, he proved that the convex hull of the $n-b y-n$ permutation matrices which represent transpositions consists of the doubly stochastic matrices with trace $n-2$.

(3) Subsequent work on some themes of this project (specifically, optimal facility location and optimization of network operations) will be reported under a new project "Mathematical Algorithms and Models of Operations Research" to be initiated in July 1973. 
(1) J. Edmonds and Peyton Young (CUNY). Matroid designs. Journa1 of Research NBS, 77B (1973), 15-45.

(2) J. Edmonds. Edge-disjoint branchings. Submitted to a technical journal.

(3) J. Gilsinn and C. Witzgall. A performance comparison of labelling algorithms for calculating shortest path trees. NBS Technical Note $772(3 / 73)$.

(4) W.A. Horn. Minimizing average flow time with parallel machines. Operations Research, 21 (1973), 846-847.

(5) W.A. Horn. Optimal design of sorting networks. Submitted to a technical journal.

(6) W.A. Horn. Some simple scheduling algorithms. Submitted to a technical journal.

\section{LINEAR AND NON LINEAR PROGRAMMING}

Task 205-12-2050153

Origin and Sponsor: NBS

Manager: W.G. Ha11

Authorized $12 / 30 / 60$

Full task description: October-December 1960 issue, p.3

Status: TERMINATED

(1) R.H.F. Jackson continued the acquisition of mathematical programming algorithms from other institutions. Codes for linear, nonlinear and integer programming were obtained from cornell and the University of Wisconsin; a code for generating large-scale (uncapacitated) network problems as an aid to algorithm evaluation was secured from the University of Texas. Further assimilation (i.e., familiarization and systematic testing) of these codes during FY 1974 is indicated.

(2) Jackson and P.B. Saunders converted the NBS linear and quadratic programming routines to EXEC 8. T.B. Ayers revised forthcoming documentation on supplementary routines for ranging and parametric analyses.

(3) Need for consultation services in mathematical programming, and for reliable codes like the NBS linear programing routines and the NBS-sponsored dynamic programming algorithms, remains quite heavy among many government groups. Such assistance was provided to the AEC, Federal Rail Administration, Social Security Administration, Agriculture Department, Tariff Commission, and 4 Forestry Service sites, as well as NBS staff. P.B. Saunders performed most of these consultations.

(4) Work continued by A.J. Goldman, W.A. Horn and M.H. Pear1 on applying a previously-developed minimax estimation technique to two bivariate problems, one involving the estimation of transit-line flows.

(5) The theme which has recently dominated this project, that of meeting the keen need in the governmental and general technical communities for high-quality solution algorithms for recurrent classes of problems in mathematical operations research, will be continued under a new project "Mathematical Algorithms and Models of Operations Research" to be initiated in July 1973.

\section{Publication}

(1) A.J. Goldman. Scheduling a time shared server to minimize aggregate delay. Journal of Research NBS, 76B (1972), 109-117. 
Task 205-12-2050586

Origin: NBS (Div. 431) Authorized $7 / 15 / 71$

Sponsor: NBS, varlous other agencles

Manager: A.J. Goldman

Full task description: July-December 1970 issue, p.8

Status: CONTINUED

(1) Project 4310900: A.J. Goldman particlpated in a number of project and document reviews for the sponsoring division.

(2) Project 4314431: A.J. Goldman, W.G. Hal1 and W.A. Horn (w1th Dr. H.J. Oser 205.01) completed participation in this project, to assist DOT's Urban Mass Transportation Administration in several systems-analysis tasks. Some 20 contractor reports and proposals were evaluated during FY 1973.

(3) Project 4314487: P.B. Saunders and R.H.F. Jackson continued collaboration in this study, to aid the Army Nurse Corps in personnel-level planning. A simulation model, incorporating historical data and current policies (on attrition, promotions, etc.) was designed to project Corps strength in varlous rank-spectality categorles; the model was programmed, tested and 1s being documented.

(4) Project 4314552: A.J. Goldman continued consultation on this project, to evaluate the Shirley Highway Express Busway Demonstration Project. Emphasis this period was on monitoring a contracted study on modal-split modelling.

(5) Profect 4314518: W.G. Hall, with T.B. Ayers, J. Gilsinn and L.S. Joel, continued participation 1n this study of the lead-paint polsoning problem. Gilsinn was involved in the planning phase. Hall directed and Ayers participated in a methodology-testing survey of District of Columbia housing untts, involving X-ray fluorescence lead detectors, with a reading being taken in each room from each wall, the baseboard, a window sill or frame, etc. High lead levels were found in a number of older dwellings. These results are being documented, along with preparation of a manual to advise authorities in other clties on the conduct of such surveys. Joel analyzed data on lead content in 250 small cans (under 5 gallons) from 5 retall outlets, and is documenting the findings and implications.

(6) Project 4314568: This involves systems studies in support of NBS' office of Weights and Measures. Assistance was provided in refining a methodology for estimating the "misflow" of dollars due to faulty weighing and measuring devices. P.B. Saunders, with T.B. Ayers and M.H. Pearl, began efforts to develop a model describing the dependence of the device performance upon inspection policy, in particular interviewing persons associated with the manufacture, sales and services of such devices, and opening a dialog with the scale manufacture industry in search of baslc data. A.J. Goldman and M.H. Pearl are analyzing some simplified game-theoretic models concerning the dependence of the performance of a W\&M inspection system upon penalty levels and inspection resources. W.G. Hall with Goldman examined some legal literature and other sources as a start toward elucidating the concept of "equity in the marketplace" which is the basis for the Bureau's welghts \& measures activities. Documentation of this work, performed during the last quarter of FY 1973, is in progress.

(7) Project 4314427: J. Gilsinn, R.H.F. Jackson and L.S. Joel are participating in this study, to assist the FAA by examining that agency's needs for alr traffic level projectlons for various analyses, identifying common elements among these needs, and recommending approachs to meet these common needs in a consistent and efficlent way. During FY 1973 effort was focussed on: a survey to identify the requirements for traffic projects, a preliminary structuring of data needs, and initialization of a search for data sources. 


\section{PROBABILITY AND MATHEMATICAL STATISTICS}

\section{RESEARCH IN PROBABILITY AND MATHEMATICAL STATISTICS}

Task 20503-12-2050131/63-1259

$6030-11$

Origin: NBS

Manager: Joan Raup Rosenblatt

Authorized $10 / 1 / 62$

Full task description: July - December 1962

Status: CONTINUED. Wesley L. Nicholson (Institute for Basic Standards Visiting Scientist) worked, in collaboration with David Hogben and Sally T. Peavy, on algorithm development and implementation for several new "resistive" procedures for data analysis. Effective exploratory data analysis requires statistical techniques that both (1) display and evaluate the agreement between observations and hypothesized theoretical representations and (2) call attention to the existence and nature of discordant observations. The name "resistive" is given to techniques that achieve a useful adjustment of observations in spite of the presence of outliers.

Substantial progress was made in the development of a high quality, portable computer program for the "stem and leaf" technique of exploratory data analysis. The stem and leaf diagram is similar to a histogram in that it displays the frequency distribution of a set of data, but it does more: the variation within intervals can be inspected, and selected order statistics are indicated. Thus the stem and leaf diagram is a technique for studying the frequency distribution of measurement data in order to formulate mathematical models and to evaluate "outlying" values, so that summary measures (average, standard deviation) can be correctly interpreted.

The "median polish" procedure is an alternative to the common technique for analysis of a two-way table by estimating row and column averages. An iterative adjustment is performed using row and column medians. David Hogben and Sally T. Peavy collaborated with Nicholson to develop a median polish subroutine and to examine the results obtained in analyses of several experiments.

The "BIWEIGHT" procedure was, like the two above, originally proposed by John W. Tukey (Princeton and Bell Labs). It represents a general approach to iterative adjustment of least squares fits using weights determined by the residuals (deviations of observations from trial fits). Nicholson investigated a version of BIWEIGHT advocated by David F. Andrews (Univ. of Toronto), along with other modifications of simple least squares, in application to X-ray crystal structure analyses. This work will be continued by Nicholson, in collaboration with Edward Prince (NBS Reactor Radiation Division) with applications to neutron diffraction crystal structure analysis.

\section{Publications:}

(1) Tables of two-associate-class partially balanced designs. Willard H. Clatworthy (State Univ. of New York, Buffalo), with contributions by J. M. Cameron (Office of Measurement Services) and J. A. Speckman. NBS Applied Math. Series 63, May 1973.

(2) Design and analysis of experiments. Mary G. Natrella. To appear as a chapter in the third edition of Quality Control Handbook (J. M. Juran, ed.).

(3) The t-statistic for a double exponential distribution. Raymond C. Sansing. Submitted to a technical journal.

(4) Some recent developments in linear least squares computations. Roy H. Wampler. To appear in Proc., Computer Science and Statistics: Sixth Annual Symposium on the Interface, Berkeley, California, October 16-17, 1972. 
Full task description: July - December 1968

Status: CONTINUED. OMNITAB II, which had been implemented under the Exec II operating system, was modified to be a processor under the Exec 8 operating system. The transition from Exec II to Exec 8 was remarkably smooth with virtually no disruption to the users. Continued development included the correction of minor errors and the modification of some subprograms so that they could be used independently of OMNITAB. 


\title{
COLLABORATION ON STATISTICAL ASPECTS OF
}

\author{
NBS RESEARCH AND TESTING
}

Task 13911-612050950/51-1 9500-11

Origin: NBS

Managers: H. H. Ku, J. R. Rosenblatt

Authorized $7 / 1 / 50$

Full task description: July - September 1950 issue, p. 60

Status: CONTINUED. This is a continuing project involving cooperation with other Bureau scientists on the statistical aspects of their investigations. These services vary from short (one-hour) sessions to extended collaborations involving several man-months; and are concerned primarily with statistical design of experiments, analysis and interpretation of data, and the use of computers in statistical analysis of data. Typical examples of services performed are the following.

W. L. Nicholson and H. H. Ku collaborated with B. N. Taylor (Absolute Electrical Measurements Section) in the analysis of U.S.S.R. measurements of the proton gyromagnetic ratio. There were 38 values of $\gamma_{p}^{\prime}$ obtained between 1960-1968 using 12 different solenold coils. The result of the analysis showed

(1) there was one outlier that should be excluded from the data, (2) the between coil component was small compared to measurement errors, and (3) the apparent increasing trend with time was confounded with coils. Semi-weighted mean techniques were also used as an alternative method of analysis, and the random component of uncertainty was computed using several different models for comparison.

Harry $\mathrm{Ku}$ assisted Lucy Caval1o (Radioactivity Section) in the analysis of 100 ampules of Cs-137 to be used as nuclear fuel burn-up standards. The activities of these ampules, measured once in April and once in September of this year, can be certified either for individual ampule, or for the entire lot of 100 allowing for differences among ampules. Individual certification was recommended to assure the unbiasedness of the estimate of activity for each ampule; since there was evidence that the activity depends on weight and that the ampules differed in weight of contents.

David Hogben has assisted E. S. Newman (Materials Reference Laboratories Section) to improve his FORTRAN programs for analysis of laboratory test results for two kinds of asphalt (soils, aggregates and cements). The programs (over 5000 statements) are used five or six times every other month. A run may take over 15 minutes and produce over 2000 pages of output. Results are sent to state highway materials engineers. Programs print: ordered lists of tests results, Youden plots, statistical analyses and reports concerning agreement with precision statements in American Association of State Highway Officials (AASHO) and ASTM specifications.

James J. Filliben has been assisting Gilbert Ugiansky (Metallurgy Division, Corrosion Section) in the analysis of an ASTM interlaboratory stress corrosion testing program. The purpose of the program is to characterize and assess three proposed test procedures (instrumental configurations) to be used in stress corrosion testing of aluminum alloys containing copper. The test procedures in question are employed, for example, by the Air Force in the testing of aluminum to be used in aircraft construction.

The techniques utilized in the analysis were presented as a case study in data analysis in an Applied Mathematics Division Expository Seminar Series lecture on June 11 . The conclusions of the analysis were presented to an ASTM test group in Philadelphia on June 25.

James J. Filliben has been collaborating with Emil Simiu (Center for Building Technology) in the analysis of daily maximum wind velocities for six cities: Washington ( 5 years worth), Miami ( 3 years), Great Falls, Montana ( 3 years), Denver ( 3 years), Chicago (10 years), and Trenton, New Jersey ( 5 years). of ultimate interest is to be able to predict, from probabilistic considerations, the maximum wind velocity for a longer (20,50, or 100 years) time period. On the basis of these predicted extremes, existing building and structure codes may be confirmed or modified accordingly.

Use of computerized probability plot procedures demonstrated that for all six cities, the daily maximum wind velocities closely followed a Weibull distribution with tail length parameter 2 (i.e., a Rayleigh distribution). Location and scale estimates for each individual city were also obtained. Estimates of the distribution of the maximum value for 20, 50, and 100 year periods were derived using both exact order statistic theory and asymptotic extreme value theory. 
John F. LaBrecque and Peter V. Tryon have been participating actively in the planning, preliminary data analysis, and evaluation of several automated measurement systems in the Electromagnetics Division, in collaboration with E. L. Komarek and F. X. Ries (Circuit Standards Section) and W. Yates (Power-Current-Voltage Standards Section) and others. The activities can be divided into three areas: (1) inftial experimentation, "feeling out" the Automatic Network Analyzer (ANA); (2) measurement evaluation, for calibration services and measurement assurance programs; (3) future improvements of the ANA, involving the interaction among hardware changes, mathematical models, and experiment design and analysis.

In the first two areas, substantial progress has been made in the study of measurements of the quantities: power, magnitude and phase of reflection coefficient, and attenuation. In each case the objective has been to study the nature of the random variation of the system through planned experimentation and components of variance analysis. The total variation among measurements has been separated into components due to connectors, tuning of the ANA, unexplainable (physically) day to day variation and short term error. Problem areas can then be isolated such as the following situation. For the impedance parameters the random component due to tuning proved to be serious. The tuning procedure is now roughiy equivalent to fitting a circle to only 3 points in the $x, y$ plane. Tryon and LaBrecque suggested that an improvement could be made by taking additional measurements following a designed experiment and using non-linear least squares analysis to fit the circle. They are assisting with the development and evaluation of software for the ANA to implement this.

Peter V. Tryon and John F. LaBrecque have been developing innovative approaches to the teaching of statistics for scientific and engineering laboratory staff members.

Tryon has been teaching a two-semester University of Colorado course, Statistical Methods in Research, making extensive use of OMNITAB as a teaching tool, for example in the presentation of analysis of variance with emphasis on concepts and interpretation instead of algebraic and arithmetic drudgery. The second semester, dealing with regression methods, has led to a cooperative investigation of a variety of least squares computer programs now in use at the Boulder laboratories.

A seminar series on "the evaluation of measurement processes" has attracted approximately 20 participants organized into four discussion groups, two groups meeting with Tryon and two meeting with LaBrecque. Using John Mandel's "The Statistical Analysis of Experimental Data" as a text, the groups are also working with examples drawn from NBS work and using the OMNITAB computing system.

\section{Pub1ications:}

(1) Confidence limits for the abscissa of intersection of two linear regressions. James J. Filliben and John E. McKinney (Polymers Div.). NBS J. Res. - B. Math. Sclences, Vol. 76B (1973), pp. 179192.

(2) A user's guide to the OMNITAB command "STATISTICAL ANALYSIS". H. H. Ku. NBS Technical Note 756, March 1973.

(3) Material variability as measured by low temperature electrical resistivity. Alan F. Clark (Cryogenics Division) and Peter V. Tryon. Cryogenics, Vol. 12 (1972), pp. 451-461. 
Origin: Various Agencies

Sponsor: NBS

Manager: J. R. Rosenblatt

Full task description: January - March 1958 issue, p. 45

Status: CONTINUED. This is a continuing project which involves providing, upon request, statistical services to other governmental agencies, universities, industrial organizations, and other nongovernmental agencies. Approximately 40 such requests are handled per month ranging from short conferences to collaboration involving several days work.

The Department of Commerce, Office of Telecommunications sought help in preparing to monitor the effect of a telephone rate structure change made in Colorado in October 1972. (The method for charging for installation service has been changed from flat rate to actual cost.) Using data on the number of telephones installed each month from January 1967 to September 1972, Peter V. Tryon developed a prediction model from which one can calculate the number of telephone installations that would be expected to occur under the old rate structure. In supplementary studies, similar prediction models were developed for other variables, and the use of economic variables to improve projections of annual growth was investigated.

\section{Publications:}

(1) Comments on 'Treatment of null responses' by Genevieve L. Meyer and Ronald L. Johnson. James J. Filliben. To appear in Proc. 17th Conf. on Design of Experiments in Army Research, Development and Testing, Oct. 27-29, 1971, Report No. 72-2, U. S. Army Research Office Durham, Sept. 1972, pages 397-402.

(2) Statistical methods applicable to counting experiments and evaluation of experimental data. H. H. Ku. To appear in Proc. First International Summer School on Radionuclide Metrology, Herceg Novi, Yugoslavia, August 21-31, 1972.

(3) Effective statistical tests for detection models. James A. Lechner. To appear in Proc. Military Operations Research Soc. Symposium, Dec. 12-14, 1972, Fort Lee, Virginia. 
RESEARCH IN NUMERICAL ANALYSIS AND RELATED FIELDS

Task 20501-12-2050110/55-55

$1540-11$

Origin: $\quad$ NBS

Manager: Morris Newman

Full task description: July - September 1954 issue, p. 1

Status: CONTINUED. A survey of programs for computing the inverse of a matrix was undertaken by K.E. Fitzgerald, at the suggestion of M. Newman. The programs were compared primarily on the basis of execution time and accuracy. Accuracy estimates were included, and several of the programs using "iterative refinement" were tested both with and without this option. It appears that for matrices of small order (say at most 50) improvement procedures are worthwhile, but for matrices of large order (say more than 100) their use is not always justified. Two other points emerged: the need for some kind of error estimate in the output of any good inversion program, and the superiority of $N(A B)$ over $N(A) N(B)$ [here $N(A)$ is some norm of the matrix(A) $j$ in computing error estimates involving matrices.

Improved versions of the multi-length euclidean algorithm and the multi-length quotient and remainder algorithm were written by $M$. Newman and incorporated into his program for the exact solution of linear systems of equations. One of the versions of this program now produces the solution as quotients of relatively prime integers, and does so in a moderate amount of time. Thus for a typical system of 50 equations in 50 unknowns the running time is approximately 30 seconds on the UNIVAC 1108 computer.

M. Newman has prepared programs for arbitrary precision computation with decimals and with integers. A program to compute the exponential function to any number of decimals was written and has been thoroughly checked out. A program to compute the invariant factors and elementary divisors of an integral matrix using arbitrary precision integer arithmetic is in process of being written.

M. Newman has proved that if $a_{1}, a_{2}, \ldots, a_{n}$ are elements of a principal ideal ring $R$ such that $\left(a_{1}, a_{2}, \ldots, a_{n}\right)=1$, and if $n \geq 3$, then the row $\left(a_{1}, a_{2}, \ldots, a_{n}\right)$ may be completed to a symmetric matrix of $\operatorname{SL}(n, R)$. As a consequence of this result it is shown that if $R$ is a $f i e l d$, then every element of $S L(n, R)$ is the product of a fixed number of symmetric matrices of $\mathrm{SL}(\mathrm{n}, \mathrm{R})$ except when $\mathrm{n}=2, \mathrm{R}=\mathrm{GF}(3)$, which is a genuine exception.

M. Newman also showed that if $A$ is an integral matrix such that $A \equiv A^{T} \bmod m$ and det $A \equiv 1 \bmod m$, where $m$ is odd, then there is an integral matrix $B$ such that $B$ is symmetric, det $B=1$, and $B \equiv A \bmod m$. The result is false if $m$ is even.

M. Newman and M. Sheingorn have studied a class of functional equations and have proved that they possess non-trivial continuous solutions. A key result is the following: Let $a_{1}, a_{2}, \ldots, a_{n}$ be distinct real numbers. Then the entire function $\sum_{k=1}^{n} e^{a_{k}{ }^{2}}$ always has a zero, provided $n \geq 2$. M. Newman has shown that if $M=\left[\begin{array}{ll}A & B \\ 0 & C\end{array}\right]$ is a partitioned matrix over a principal ideal ring $R$, and if $(\operatorname{det} A, \operatorname{det} C)=1$, then the invariant factors of $M$ are the same as the invariant factors of $\left[\begin{array}{ll}A & 0 \\ 0 & C\end{array}\right]$; i.e. the matrix $B$ contributes nothing to the Smith normal form of $M$. This is a useful computational result. 
M. Newman has initiated work on the group generated by $\left(\begin{array}{ll}1 & \zeta \\ 0 & 1\end{array}\right),\left(\begin{array}{ll}1 & 0 \\ \zeta & 1\end{array}\right)$, where $\zeta$ is a root

of unity. He conjectures that this group is never free, and has proved this conjecture in two cases; namely, when $\zeta$ is a $2^{n}$ th root of unity, and when $\zeta$ is a pth root of unity, where $p$ is a prime having 2 as a primitive root.

The posthumous book "Topics in Analytic Number Theory" by H. Rademacher, which was edited by M. Newman, J. Lehner, and E. Grosswald, has now appeared as a Springer publication in their "Ergebnisse" series.

C.R. Johnson continued his work on a number of matrix theory and related problems. These primarily involved eigenvalues and the inertia of matrix products. He showed that all powers of a square matrix $A$ have positive definite hermitian part if and only if $A$ is positive definite hermitian. Also related to investigating powers of matrices, Johnson and Newman showed that there is essentially only one exception to the following statement: let $\alpha, \beta, \gamma$ be distinct complex numbers of unit modulus; then there is a positive integer $m$ such that 0 is in the convex hull of $\alpha^{\mathrm{m}}, \beta^{\mathrm{m}}, \gamma^{\mathrm{m}}$ 。 With C.S. Ballantine (Oregon State University), Johnson completed classifying the set products of certain positivity classes. Continuing his investigation of D-Stability, Johnson provided parallel necessary and sufficient conditions involving real and complex quadratic forms respectively. For the field of values of a matrix he gave an inclusion set computable directly from the entries. For tree graphs Johnson also showed how to label the nodes to attain minimum edge difference. This is an initial case of a problem arising in simplifying the computation of the finite-element method of structure analysis.

\section{Publications:}

(1) Commutators as products of squares. M. Newman and R.C. Lyndon. To appear in Proc. Amer. Math. Soc.

(2) Products of powers in groups. M. Newman, R.C. Lyndon, and T. McDonough. To appear in Proc. Amer. Math. Soc.

(3) Modular quotient groups. M. Newman. To appear in Illinois J. Math.

(4) Diophantine equations in cyclotomic fields. M. Newman. To appear in J. Reine Angew. Math.

(5) Units in arithmetic progression in an algebraic number field. M. Newman. To appear in Proc. Amer. Math. Soc.

(6) Symmetric completions and products of symmetric matrices. M. Newman. To appear in Trans. Amer. Math. Soc.

(7) A result on integral symmetric matrices. M. Newman. To appear in Linear and Multilinear Algebra.

(8) The Smith normal form of a partitioned matrix. M. Newman. In manuscript.

(9) Continuous solutions of a homogeneous functional equation. M. Newman and M. Sheingorn. In manuscript.

(10) Comparison of some FORTRAN programs for matrix inversion. K.E. Fitzgerald. To appear in J. Research NBS, Section B.

(11) On the eigenvalues of $A+B$ and $A B$. H. Wielandt. Edited by C.R. Johnson. Journal of Research NBS, 77B $(1973), 61-63$. 
(12) Gersgorin sets and the field of values. C.R. Johnson. To appear in J. Math. Anal. and Appl.

(13) A note on matrix solutions to $A=X Y-Y X$. C.R. Johnson. To appear in Proc. Amer. Math. Soc.

(14) A Lyapunov theorem for angular cones. C.R. Johnson. To appear in the Journal of Research NBS, Section B.

(15) Hadamard products of matrices. C.R. Johnson. To appear in Lin. and Multilin. Alg.

(16) The Hadamard product of $A$ and $A^{*}$. C.R. Johnson. To appear in Pac. J. Math.

(17) The range of $A^{-1} A^{*}$ in $G L(n, C)$. C.R. Johnson and C.R. DePrima. To appear in Lin. Alg. and Applics.

(18) A Gersgorin inclusion set for the field of values of a finite matrix. C.R. Johnson. To appear in Proc. Amer. Math. Soc.

(19) Triangles generated by powers of triples on the unit circle. C.R. Johnson and M. Newnan. To appear in the Journal of Research NBS, Section B.

(20) Powers of matrices with positive definite real part. C.R. Johnson. Submitted to a technical journal.

(21) Minimum edge difference node labelling of tree graphs. C.R. Johnson. (Work in Progress)

(22) Accretive matrix products. C.R. Johnson and C.S. Ballantine. (Work in Progress)

(23) D-Stability and rea1 and complex quadratic forms. C.R. Johnson. (Work in Progress) 
Origin: NBS (Division 462)

Sponsor: HUD

Manager: Russel1 A. Kirsch

Status: NEW. A residential community under construction in New Jersey generates 1 ts own energy. Instrumentation supplied by NBS monitors energy generation, distribution and consumption as well as energy-related parameters like temperatures, pressures and flow rates. We are assisting the Center for Bullding Technology in the task of planning the data acquisition system, designing editing procedures and programs for producing archival records, and analyzing the data to determine trends in the performance of the total energy system. When the system goes into operation (estimated in early 74) the fine structure of the behavior of all energy parameters sampled every 5 minutes for a year on 300 variables will be analyzed. During the current period early planning efforts were the main involvement.

\section{ARTIFICIAL INTELLIGENCE}

Task 2050104

Origin: NBS

Manager: Russell A. Kirsch

Status: NEW. The PDP-10 LISP Processing Language built at NBS (see project description for Task 2050404 Jan-June 1972, p. 14) is belng used for the analysis of images obtained from Earth Resources Satellites. Image decomposition and reconstruction algorithms prevlously developed for biological purposes were used to analyze, reconstruct and spectrally classify a view of the NBS site from $925 \mathrm{~km}$ in space. 
Origin and Sponsor: NBS

Manager: I. A. Stegun

Full task description: July-December 1964 1ssue, p. 4.

Status: CONTINUED. Consultations continued at the rate of about 10 per month with staff of NBS, other goverment agencles, industry and universities. Topics covered for the most part were approximations, computing techniques and pitfalls.

The 10 th printing (corrected) of the Handbook of Mathematical Functions was released by the Government Printing Office, December 1972. The 7th printing(paperback) by Dover Publications, Inc. was also recently released. Questioned 1tems are checked and an errata list is maintained covering all printings of the volume.

As a consequence of the consulting work and checking of the citation index, exploratory work was started on the evaluation of the sine, cosine and exponential integrals, Si(x), Ci(x) and Ei(x). The numerical evaluation of more complicated integrals is frequently alded by expansions in terms of these functions. Recent applications have been found in the estimation of the characteristics of photochromic materials as a recording medium for phase holograms, investigations of radiation impedance of a long narrow rectangular baffled piston and spectrophotometric linearity testing using the double-aperture method. Limiting values, zeros, maxima and minima, practical bounds of various computing methods, pitfalls, critical values, etc., will all be discussed in a forthcoming paper. A many place radix table will also be supplied.

An automatic integration routine will be made generally avallable after undergoing further testing. It has been used thus far in connection with the evaluation of various special functions under study.

Publications: Handbook of Mathematical Functions, AMS 55, Tenth Printing (with corrections), December 1972 .

Automatic Computing Methods for Special Functions. Part II. The Exponential Integral $E_{n}(x)$. Irene A. Stegun and Ruth Zucker. In process. 


\title{
Lectures and Technical Meetings
}

\author{
Papers and Invited Talks \\ Presented by Members of the Staff at Meetings \\ of Outside Organizations
}

COLVIN, Burton $\mathrm{H}$.

FONG, Jeffrey T.

GILSINN, Judith F.

HOGBEN, David

JOHNSON, Charles R.

KRAFT, S. Richard

NEWMAN, Morris

NICHOLSON, Wesley L.

OLVER, Frank W. J.

ROSENBLATT, Joan R.
"Mathematics - Irrelevant, Indifferent or Indispensable?". 1973 National Council of Teachers of Mathematics, San Francisco, California. March 24.

On the Applicability of the Bernstein-Kearsley-Zapas Theory of Incompressibility. 43rd Annual Meeting, Society of Rheology, Cincinnati, Ohio. January 31.

An Application of Schur's Lemma on Irreducible Sets of Matrices in Continuum Mechanics. Naval Ordnance Laboratory, White Oak, Silver Spring, Maryland. February 16.

Experimental Definition of Non-Equilibrium Entropy for Aluminum and Stainless Steel. Fourth Canadian Congress for Applied Mechanics (CANCAM 73), Ecole Polytechnique de Montreal, Quebec, Canada. May 28.

Estimating the Nationwide Incidence of Lead Paint Poisoning. 43rd National Meeting, 0RSA. Milwaukee, Wisconsin. May 11.

Statistical Problem - Solving Using the OMNITAB II Computing System. Washington Statistical Society. March 5.

Panel Discussion: Can A Hardware Man Find A Home in Software? IEEE Symposium on Computer Software Reliability, New York, New York. May 1.

Triangles Generated by Powers of Triplets on the Unit Circle, Mathematical Association of America - Spring Meeting 1973 - Maryland - District of Columbia - Virginia, Hampton Institute, Hampton, Virginia. April 28.

A-priori Inequalities for Semidiscretizations of Parabolic Equations. SIAM National Meeting of 1973, Hampton, Virginia. June 18.

Some Number-Theoretic Computations. American Mathematical Society, 79th Annual Meeting, Dallas, Texas. January 26.

Computations with Large Numbers. University of Toledo, Toledo, Ohio. April 9.

Some Revised Approaches to X-ray Crystal Structure Analysis Computations. Conference on Critical Evaluation of Chemical and Physical Structure Information, Dartmouth College, New Hampshire. June 24.

Legendre and Whittaker Functions with Large Parameters. American Mathematical Society, Norris Center, Northwestern University, Evanston, I11inois. Apri1 28.

Discussion of Papers on "Adaptive Estimators for Statistical Inference". Biometric Society (ENAR), Ithaca, New York. June 1. 
OLVER, Frank W. J.

BABUSKA, I.

JOEL, Lambert S.

KRUSKAL, Joseph B.

NICHOLSON, Wesley L.

FILLIBEN, James J.
( Institute for Fluid Dynamics, University of Maryland and Applied Mathematics Division, NBS). Liouville-Green (or WKB) Approximation. January 11.

(Institute for Fluid Dynamics, University of Maryland, College Park, Maryland). Numerical Solution of Elliptic Partial Differential Equations. February 8 .

Cluster Analysis for Information Retrieval. March 15.

(BeIl Telephone Laboratories, Murray Hill, New Jersey). Multidimensional Scaling and its Bright New Youngster: Individual Differences Scaling. Apri1 12.

(Battelle Memorial Institute and Visiting Scientist, IBS). Exploratory Data Analysis. May 10.

A Case Study in Techniques of Data Analysis - An Interlab Fatigue Time Experiment. June 11 .

Applied Mathematics Division Special Seminar Series

(Auspices of the NBS Fracture Mechanics Seminars - Dr. R. M. Thomson, Coordinator)

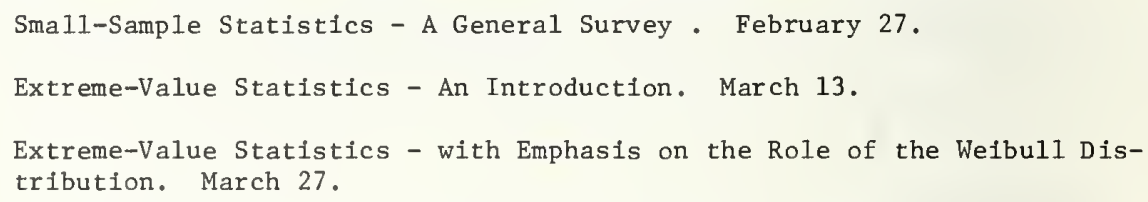

FONG, Jeffrey T.

OSER, Hans J.

ASKEY, Richard

WALKUP, David W.

BARAHA, Sami

MARSAGLIA, George

DEPRIT, Andre
Statistical Theories of Fracture - Mathematical Pitfalls. May 8.

\section{Applied Mathematics Division Meetings}

A "Mathematical" Review of Statistical Theories of Strength and Fracture. April 10.

On Statistical Dislocation Theories of Brittle Fracture. April 24.

(University of Wisconsin, Madison, Wisconsin). New Positive Sums and Integrals with Applications to Harmonic Analysis and Quadrature Problems. February 1.

(Washington University, St. Louis, Missouri). The Circuit of Maximum Average Weight in Directed and Undirected Graphs. April 16.

(The Johns Hopkins University, Baltimore, Maryland). The Four Color Problem - An Approach Through Algebra and Analysis. May 17.

(McGill University, Montreal, Canada). Recent Developments and Future Trends in Random Number Generation. June 11.

(Cincinnati Observatory, University of Cincinnati, Ohio). Mechanized Algebraic Operations. June 25.

Tracing an Assembler Program. June 26. 
KIRSCH, Russe11 A.

LOZIER, Danlel W. MAXIMOIN, Leonard C. (240)

ORSER, Donald J.

SADOWSKI, Walter L*

KIRSCH, Russell A.

OSER, Hans J.

WAMPLER, ROY H.

PEAVY, Sally T.

TRYON, Peter V.

KIRSCH, Russel1 A.

NEWMAN, Morris
The Measurement of Complexity. June 26.

NBS In Action II

Computer Sclence and Technology, June 26

Improving the Quality of Mathematical Software Through Testing and Validation.

Pattern Recognition In Earth Resources Views from Space.

One-Lane Traffic Ahead; On-Line Repair of Computer Algorithms.

Accurate Linear Least Squares Computer Programs.

$\underline{\text { In-Hours Courses, Spring Semester }}$

FORTRAN Programming for Beginners, NBS Graduate School.

Statistical Methods In Research, University of Colorado.

NBS Visit

2nd USA Mathematical Olympiad Winners Applied Mathematics Division Presentation

Remote Interactive Computing. June 29.

Number Theory and Computers. June 29.

* Person presenting the paper. 


\section{Publication Activities}

\subsection{PUBLICATIONS THAT APPEARED DURING THIS PERIOD}

1.1 Tables

Tables of Two-Associate-Class Partially Balanced Designs. W. H. Clatworthy (SUNY, Buffalo), with J. M. Cameron (Office of Measurement Services) and J. A. Speckman. NBS Applied Mathematics Series 63, May 1973.

1.2 Manuals

A User's Guide to the OMNITAB Command "STATISTICAL ANALYSIS". H. H. Ku. NBS Technical Note 756, March 1973.

1.3 Technical Papers

Matroid Designs. J. Edmonds and Peyton Young (CUNY). J. of Research NBS 77B(1973), 15-45.

Comments on the Paper "Treatment of Null Responses" by Genevieve L. Meyer and Ronald L. Johnson. James J. Filliben. Proc. 17th Conf. on the Design of Experiments in Army Research, Development and Testing, Walter Reed Army Medical Center, 27-29 October 1971, Report No. 72-2, U. S. Army Research Office - Durham, September 1972, pages 397-402.

Confidence Limits for the Abscissa of Intersection of Two Linear Regressions. James J. Filliben and John E. McKinney (Rheology Section). J. of Research NBS 76B (1972), 179-192.

Product Solutions and Separation of Variables. A. J. Goldman. J. of Research NBS 76B (1972), 201-204.

Scheduling a Time-Shared Server to Minimize Aggregate Delay. A. J. Goldman. J. of Research NBS 76B (1972), 109-117.

Material Variability as Measured by Low Temperature Electrical Restivity. Alan F. Clark (Cryogenics Division) and Peter V. Tryon. Cryogenics, Vol. 12 (1972), 451-461.

On the Eigenvalues of $\mathrm{A}+\mathrm{B}$ and $\mathrm{AB}$. H. Wielandt. Edited by C. C. Johnson. J. of Research NBS 77B (1973), 61-63.

1.4 Reviews and Notes

Minimizing Average Flow Time with Parallel Machines. W. A. Horn. Operations Research, 21 (1973), 846-847.

1.5 Books

Handbook of Mathematical Functions, AMS 55, Tenth Printing (with corrections), December 1972.

1.8 Technical Notes

A Performance Comparison of Labelling Algorithms for Calculating Shortest Path Trees. J. Gilsinn and C. Witzgall. NBS Technical Note $772(3 / 73)$.

\subsection{MANUSCRIPTS IN THE PROCESS OF PUBLICATION}

2.2 Manuals

Design and Analysis of Experiments. Mary G. Natrella. To appear as a chapter in the third edition of Quality Control Handbook (J. M. Juran, ed.).

2.3 Technical Papers

Comparison of Some FORTRAN Programs for Matrix Inversion. K. E. Fitzgerald. To appear in J. of Research NBS, Section B.

Gersgorin Sets and the Field of Values. C. R. Johnson. To appear in J. Math. Anal. and Appl. A Note on Matrix Solutions to $A=X Y-Y X$. C. R. Johnson. To appear in Proc. Amer. Math. Soc. A Lyapunov Theorem for Angular Cones. C. R. Johnson. To appear in the J. of Research NBS, Section B. 
NBS-114A (REV. 7-73)

U.S. DEPT. OF COMM.

BIBLIOGRAPHIC DATA SHEET

1. PUBLICATION OR REPORT NO.
NBSIR 74.459

NBSIR

4. TITLE AND SUBTITLE

Projects and Publications of the Applied Mathematics Division

A Semi-Annual 1 Report

January Through June 1973 $\begin{aligned} & \text { 2. Gov't Accession } \\ & \text { No. }\end{aligned}$
3. Recipient's Accession No.

5. Publication Date

6. Performing Organization Code

8. Performing Organ. Report No. NBSIR 74-459

10. Project/Task/Work Unit No.

11. Contract/Grant No.

13. Type of Report \& Period Covered

$1 / 73-6 / 73$

14. Sponsoring Agency Code

15. SUPPLEMENTARY NOTES

This is a progress report rather than a sponsor report.

16. ABSTRACT (A 200-word or less factual summary of most significant information. If document includes a significant bibliography or literature survey, mention it here.)

Descriptions are given of all new division tasks. The status of all tasks is discussed and relevant publications listed. Staff activity in lectures, seminars, courses, etc. is included as well as staff publications.

17. KEY WORDS (six to twelve entries; alphabetical order; capitalize only the first letter of the first key word unless a proper name; separated by semicolons)

Projects; publications; lectures; seminars; courses

$\overline{1}$

8. AVAILABILITY $\square$ Unlimited

X For Official Distribution. Do Not Release to NTIS

Order From Sup. of Doc., U.S. Government Printing Office

Washington, D.C. 20402, SD Cat. No. C13

[ Order From National Technical Information Service (NTIS) Springfield, Virginia 22151

\begin{tabular}{|l|c|}
\hline $\begin{array}{l}\text { 19. SECURITY CLASS } \\
\text { (THIS REPURT) }\end{array}$ & 21. NO. OF PAGES \\
UNCL ASSIFIED & 27 \\
\hline $\begin{array}{l}\text { 20. SECURITY CLASS } \\
\text { (THIS P AGE) } \\
\text { UNCLASSIFIED }\end{array}$ & 22. Price \\
\hline
\end{tabular}


Hadamard Products of Matrices. C. R. Johnson. To appear in Linear and Multilinear Algebra.

The Hadamard Product of $A$ and $A^{*}$. C. R. Johnson. To appear in Pac. J. Math.

A Gersgorin Inclusion Set for the Field of Values of a Finite Matrix. C. R. Johnson. To appear in Proc. Amer. Math. Soc.

Powers of Matrices with Positive Definite Real Part. C. R. Johnson. Submitted to a technical journal. The Range of $\mathrm{A}^{-1} \mathrm{~A}^{*}$ in $\mathrm{GL}(\mathrm{n}, \mathrm{C})$. C. R. Johnson and $\mathrm{C}$. R. DePrima. To appear in Linear Algebra and Applications.

Triangles Generated by Powers of Triples on the Unit Circle. C. R. Johnson and M. Newnan. To appear in the J. of Research NBS, Section B.

Statistical Methods Applicable to Counting Experiments and Evaluation of Experimental Data. H. H. Ku. To appear in Proc. First International Summer School on Radionuclide Metrology, Herceg Novi, Yugoslavia, August 21-31, 1972 .

Effective Statistical Tests for Detection Models. James A. Lechner. To appear in Proc. Military Operations Research Soc. Symposium, Dec. 12-14, 1972, Fort Lee, Virginia.

Modular Quotient Groups. M. Newnan. To appear in Illinois J. Math.

Diophantine Equations in Cyclotomic Fields. M. Newnan. To appear in J. Reine Angew. Math.

Units in Arithmetic Progression in an Algebraic Number Field. M. Newman. To appear in Trans. Amer. Math. Soc.

Symmetric Completions and Products of Symmetric Matrices. M. Newman. To appear in Trans. Amer. Math. Soc.

A Result on Integral Symetric Matrices. M. Newnan. To appear in Linear and Multilinear Algebra. Commutators as Products of Squares. M. Newman and R. C. Lyndon. To appear in Proc. Amer. Math. Soc. Products of Powers in Groups. M. Newman, R. C. Lyndon and T. McDonough. To appear in Proc. Amer. Math. Soc.

The t-Statistic for a Double Exponential Distribution. Raymond C. Sansing. Submitted to a technical journal.

Some Recent Developments in Linear Least Squares Computations. Roy H. Wampler. To appear in Proc. Computer Science \& Statistics: Sixth Annual Symposium on the Interface, Berkeley, California, October $16-17,1972$. 

